\title{
Erratum zu: Destination und Lebensraum
}

Harald Pechlaner

\section{Erratum zu: \\ H. Pechlaner (Hrsg.), Destination und Lebensraum, Entrepreneurial Management und Standortentwicklung, https://doi.org/10.1007/978-3-658-28110-6}

„Als Herausgeber dieses Bandes ist Prof. Dr. Harlad Pechlaner am Center for Advanced Studies Eurac Research in Bozen, Italien tätig gewesen.“

Die Schreibweise des Namens des Kapitelautors „Marcus Herntrei“ wurde korrigiert.

Die aktualisierte Version des Buches finden Sie unter

https://doi.org/10.1007/978-3-658-28110-6

https://doi.org/10.1007/978-3-658-28110-6_9

(C) Springer Fachmedien Wiesbaden GmbH, ein Teil von Springer Nature 2020 